\title{
Intuição Intelectual e Fundamentação do Conhecimento no Ensaio de uma nova Exposição da Doutrina-da-Ciência
}

Thiago S. Santoro

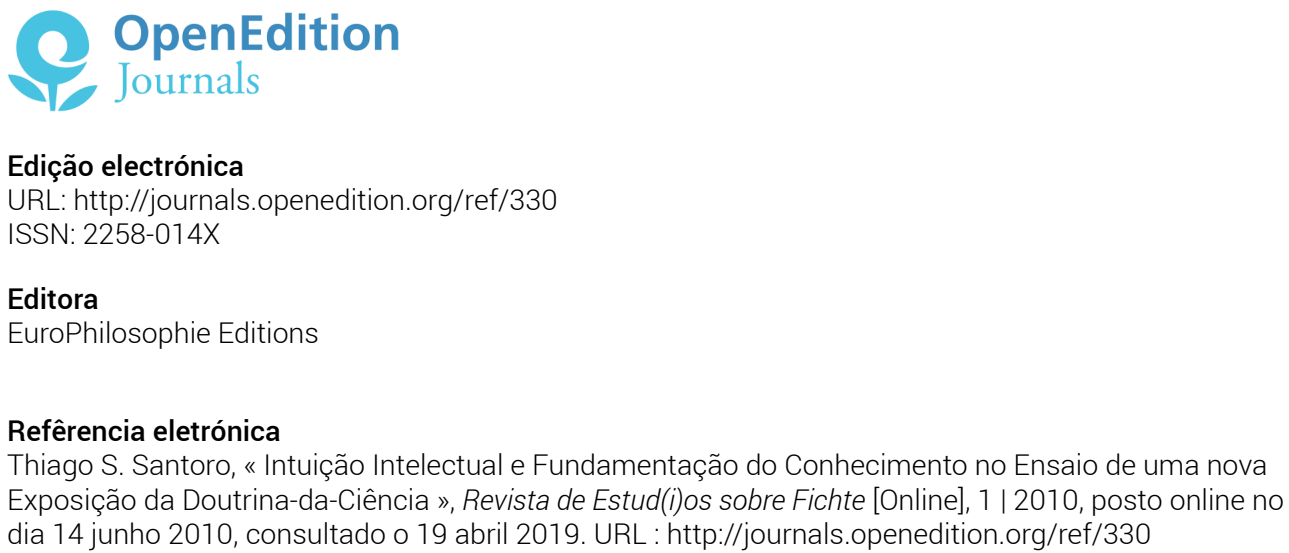

Este documento foi criado de forma automática no dia 19 Abril 2019.

(c) EuroPhilosophie 


\title{
Intuição Intelectual e Fundamentação do Conhecimento no Ensaio de uma nova Exposição da Doutrina-da-Ciência
}

\author{
Thiago S. Santoro
}

1 A exposição mais clara e extensiva do conceito de intuição intelectual, na obra de Fichte publicada pelo próprio filósofo, certamente se encontra no assim denominado Ensaio de uma nova Exposição da Doutrina-da-Ciência. ${ }^{1}$ Com a publicação desse conjunto de textos Fichte pretende acabar de uma vez por todas com os mal-entendidos que cercaram sua teoria filosófica desde o surgimento daquele manual para seus ouvintes de 1794/95, mais conhecido como Grundlage. O objetivo central do VND, e em especial da ZE, é esclarecer a verdadeira natureza do fundamento do saber, e por conseguinte também esclarecer o fundamento da própria doutrina-da-ciência, isto é, a intuição intelectual.

2 Mas o que significa uma fundamentação última do conhecimento? Responder a essa questão é, para Fichte, delimitar o sentido e a tarefa da filosofia. Seguindo o paradigma traçado por Kant na assim denominada virada transcendental, o idealismo fichtiano também define a tarefa de fundamentação do conhecimento como uma investigação sobre as condições de possibilidade da experiência. Para Fichte, assim como para a filosofia kantiana, explicitar as condições de possibilidade da experiência significa, sobretudo, mostrar aquilo que pode servir como fundamento de nossas representações necessárias, isto é, tal demonstração pretende indicar quais elementos constituem ou estruturam nossa forma de conhecimento a priori, i.e., nossos juízos de validade universal. Isso vale tanto para a estruturação do conhecimento do mundo externo quanto para aquela relativa ao conhecimento dos fenômenos internos ao sujeito, como deixa claro a seguinte passagem da Primeira Introdução à Doutrina-da-Ciência:

"Qual é o fundamento do sistema de representação acompanhadas do sentimento da necessidade, e [qual o fundamento] do próprio sentimento da necessidade? Responder essa pergunta é a tarefa da filosofia; (...). O sistema das representações acompanhadas do sentimento de necessidade se denomina também experiência: 
interna assim como externa. A filosofia tem que indicar - para dizer de outro modo

- o fundamento de toda experiência." (GA I, 4, $186 \mathrm{EE}$ ) apresenta no lugar do étimo latino 'a priori' a expressão 'sentimento da necessidade'. Qual exatamente o sentido dessa nuança no modo de descrever a tarefa filosófica? A meu ver, essa sutil inflexão já indica a grande transformação que Fichte pretende realizar dentro do projeto crítico transcendental. A idéia de um "sentimento" da necessidade parece sugerir uma reavaliação do modo como podemos determinar o caráter apodíctico de um determinado juízo. Ao invés de simplesmente postular aquilo que pode constituir um tal conhecimento necessário, como o faz Kant na primeira Critica, ${ }^{2}$ Fichte se pergunta agora como é possível conhecer justamente essa necessidade, isto é, em que medida podemos conceber a própria gênese dessa apodicticidade. ponto de vista epistêmico, que retira nossa atenção da análise das propriedades de objetos, para redirecioná-la a uma análise da própria subjetividade. (cf. GA I, 4, $186 \mathrm{EE}$ ) Tal reivindicação, entretanto, não pode ser apenas a substituição de um objeto por outro. A virada copernicana realizada pelo idealismo transcendental não pode ser reduzida a um simples deslocamento de foco, cujo objeto visado translada da objetividade do mundo a uma interioridade objetificada do sujeito. Fosse este o intuito, bastaria trocar um nome pelo outro, e teríamos inúmeras revoluções copernicanas, cada qual condicionada por um novo 'princípio', cujo termo responderia ao arbítrio cego de seu criador. Isso fica plenamente claro com a seguinte explicação de Fichte:

"no que concerne a todas as filosofias que provém antes de Kant, o Absoluto teria sido posto no ser, na coisa morta, enquanto coisa; a coisa deveria ser o em-si. (...) pois não importa como se toma esse ser, senão como se sustenta e concebe ele internamente. Esse ser é chamado certamente de Eu. Se ele é originalmente objetivado, e se aliena, então já se torna a velha coisa-em-si." (GA II, 8, 12 WL 1804²) ${ }^{3}$

Transformar o ponto de vista de nosso conhecimento significa, portanto, modificar de maneira paradigmática a própria atividade cognitiva. Nesse sentido, a inovação do idealismo transcendental fichtiano reside muito mais em revelar o processo de construção da própria consciência do que em apontar a estrutura da subjetividade como fundamento objetivo da realidade. Nesse sentido, o "observa a ti mesmo" (GA I, 4, $186 \mathrm{EE}$ ) exortado já no início da EE não representa mero jogo retórico ou força de expressão, mas é elemento metódico crucial da proposta filosófica da doutrina-da-ciência.

Da mesma forma, não se trata aqui da troca de uma ontologia realista por uma idealista (ou, como queria Hegel, de um idealismo objetivo por um subjetivo), ${ }^{4}$ pois dita permuta se resume, na verdade, a mero jogo de palavras. Se me permitem o risco da tese, gostaria de esclarecer brevemente o sentido dessa asserção, pois o resultado da contraposição entre idealismo e realismo, ou melhor, entre ontologia e epistemologia, a meu ver permite delimitar de maneira precisa a proposta filosófica fichtiana.

\section{I}

7 Ontologia só pode ser realista. A 'lógica do ser' deve explicitar aquilo que existe de modo absolutamente autônomo, aquilo que é necessariamente, independente de qualquer atividade de construção realizada pela consciência ou por um sujeito. Poderíamos assim definir o realismo ontológico ou metafísico como a defesa de uma primazia do ser na 
determinação do saber, ou ainda, como afirmação de uma prioridade lógica da objetividade frente a qualquer determinação subjetiva. Existiria assim uma espécie de logos ínsito na própria realidade enquanto tal, e o conhecimento se encontraria por ela determinado, sendo portanto mera reprodução ou captação dessa legalidade universal. No entanto, depois de Kant, não parece mais aceitável se retroceder a esse modelo de explicação do conhecimento, sem dúvida baseado na teoria clássica da verdade por correspondência, modelo predominante na história da tradição metafísica ocidental.

8 Ciente desse problema, Hegel pretende inaugurar uma nova forma de ontologia, pois necessita adequar a objetividade absoluta do ser ao paradigma kantiano (e conseqüentemente também pós-kantiano) da completa autonomia da razão. Nesse sentido, a Lógica de Hegel apresenta uma forte ambivalência, pois pode ser compreendida a um só tempo como teoria categorial do lógico, i.e., uma lógica objetiva do próprio Absoluto e do desenvolvimento ou desdobramento de suas determinações necessárias, e como teoria lógica das categorias da razão, ou seja, enquanto sistema dialético de determinações do discurso racional. Além disso, esse duplo aspecto da Lógica de Hegel determina por sua vez uma tensão entre duas esferas do projeto dialético do autor, uma esfera especulativa, outra crítica. ${ }^{5}$ Contudo, ainda que Hegel tenha considerado a esfera crítica como pré-requisito de uma fundamentação sistemática filosoficamente consistente, sem dúvida a explicitação de seu sistema revela um pendor muito maior à realização do projeto metafísico de Spinoza, o que significa dizer que o caráter crítico da argumentação de Hegel se subsume, em última instância, à estrutura autônoma e autopoiética do próprio Absoluto.

Idealismo só pode ser subjetivo. A idéia e o ideal são construções conceituais que representam autodeterminações da consciência, e tais determinações não se encontram dadas como fatos, mas estão sempre em processo de vir-a-ser, existem somente na medida em que são empregadas, e só podem ser empregadas com sentido por um sujeito. Dito de outro modo, o conhecimento é sempre uma determinação ou construção do objeto pelo eu, e assim a lógica do ser se reduz em última instância à lógica transcendental, ou seja, a investigação sobre o próprio ser dá lugar à investigação das condições de possibilidade de conhecimento do ser.

10 Alguém poderia aqui tentar objetar essa definição de idealismo dizendo, por exemplo, que Kant pretendia ver na arquitetônica transcendental da razão, tal qual apresentada em sua primeira Crítica, uma estrutura absolutamente objetiva. Ainda assim, o problema não diz respeito ao fato de existir ou não objetividade e universalidade na estrutura interna da razão, o que sem dúvida exige por sua vez uma compreensão prévia do que se entende por esses termos, mas se refere ao modo como podemos reconhecer tal validade objetiva. Afirmar que o idealismo é sempre subjetivo (abstraindo a possível conotação negativa que tal predicado, especialmente depois de Hegel, veio a representar) significa afirmar que o critério de reconhecimento da verdade do conhecimento é necessariamente ao mesmo tempo critério da constituição originária da consciência; a verdade objetiva só pode ser compreendida através de sua própria gênese na consciência pura.

11 Assim, de acordo com Fichte, só existem duas posturas filosóficas possíveis: o realismo (ou dogmatismo) e o idealismo (ou criticismo):

"Na experiência, a coisa [das Ding], aquela que é determinada independentemente de nossa liberdade, e para a qual nosso conhecimento deve se dirigir, e a inteligência, que deve conhecer, estão inseparavelmente ligadas. o filósofo pode abstrair de uma das duas, e então terá abstraído da experiência e se elevado por sobre ela. 
Abstraindo da coisa, então ele fica com uma inteligência em si, isto é, ele abstrai da relação desta com a experiência; abstraindo da inteligência, então ele fica com uma coisa em si, (...) o primeiro procedimento se denomina idealismo, o segundo, dogmatismo." (GA I, 4, $188 \mathrm{EE})$

12 Essa distinção entre idealismo e dogmatismo, tema recorrente na obra do autor, é de suma importância para se compreender o escopo da investigação fichtiana acerca do fundamento do saber. Como tentei indicar mais acima, essa diferença não diz respeito ao objeto a ser investigado, mas sobretudo ao método de investigação de qualquer objeto, mesmo que tal diferença de método de investigação também produza como resultado uma inevitável diferença na determinação do objeto. Por isso Fichte contrasta a idéia de uma 'coisa-em-si', para o autor uma tese do realismo kantiano que se mostra completamente ininteligível, com um 'Eu em si', conceito que representa (talvez ainda de modo insatisfatório ${ }^{6}$ ) a noção de uma consciência transcendental pura.

13 A bem dizer, Fichte em diversos momentos enfatiza que essas duas posições são absolutamente incomensuráveis, pois suas respectivas tentativas de explicar o fenômeno do conhecimento partem de premissas contraditórias entre si.

"Nenhum desses dois sistemas pode refutar diretamente o seu oposto: pois sua disputa é uma disputa sobre o primeiro princípio, que não pode ser deduzido; cada qual refuta o outro apenas assumindo seu próprio princípio; cada um nega tudo do [sistema] contraposto, e eles não têm um ponto sequer em comum, a partir do qual pudessem se tornar reciprocamente inteligíveis e unificáveis. Mesmo se eles parecem estar de acordo sobre a palavra de uma sentença, um a toma em um outro sentido." (GA I, 4, $191 \mathrm{EE})^{7}$

14 Mais do que isso, o filósofo assevera ainda que a postura dogmática ou realista, por ser incapaz de dar conta da idéia de liberdade humana, não constitui uma posição filosófica propriamente dita. De acordo com Fichte, a postura realista do dogmatismo, se de fato consistente, acarreta inevitavelmente o fatalismo com relação à idéia de liberdade, e um conseqüente materialismo em relação à forma de explicar a totalidade do real (o que inclui a realidade do próprio indivíduo). Assim, a incompatibilidade entre essas duas posições, especialmente no que se refere à fundamentação última do conhecimento, só pode ser solucionada, de acordo com o autor, a partir de uma escolha pessoal, ou melhor, a partir de uma revelação do verdadeiro desígnio humano enquanto ser livre. (cf. GA I, 4, 191-196) ${ }^{8}$ Vejamos em que medida essa liberdade humana radical, raiz mais profunda do projeto filosófico de todo idealismo alemão, cuja função epistêmica recebe na teoria de Fichte a alcunha de 'intuição intelectual', pode ser de algum modo compreendida.

II

Na Exposição da Doutrina-da-Ciência de 1801/2, Fichte inicia seu texto pedindo ao leitor que realize uma construção geométrica simples. "Descreve um ângulo qualquer" [...]. Fecha esse ângulo, assim descrito, com uma terceira linha reta." (GA II, 6, 135 WL 1801/02) ${ }^{10} \mathrm{Em}$ seguida Fichte pergunta ao leitor: "terias podido fechar esse mesmo ângulo com uma ou várias outras linhas (por exemplo, com alguma linha mais longa ou mais curta), além daquela com que efetivamente o fechaste?" (ibid) ${ }^{11}$ Considerando receber uma afirmativa do leitor, Fichte pergunta ainda se essa afirmação vale apenas para esse caso particular, ou para todos os ângulos possíveis; se vale apenas para o leitor enquanto indivíduo particular, ou se tal regra é válida para todos os seres racionais que compreendam suas instruções. 
16 Esse experimento pretende levantar a seguinte questão: o que permite ao indivíduo, que constrói esse triângulo determinado qualquer, ter absoluta certeza sobre a correção de sua construção, e além disso considerá-la como uma regra universal para os infinitos casos possíveis? Mais do que isso, o que permite ao mesmo indivíduo ter uma certeza imediata e indubitável, não proveniente de qualquer silogismo ou análise, dessa universalidade? A questão, portanto, não trata somente do estatuto de certeza das verdades geométricas, mas sim do estatuto da certeza per se, isto é, pergunta-se aqui sobre o que significa dizer de um conhecimento que ele é absolutamente certo.

Assim, se há um fundamento último do saber enquanto tal, ele deve ser absolutamente certo, e tal fundamento só pode ser absolutamente certo se sua certeza não se encontra condicionada por um outro princípio. Em suma, a investigação fichtiana, ao mesmo tempo movida pelo projeto fundacionista cartesiano e pelo teorema kantiano da plena autonomia da razão, pergunta, portanto, se de fato é possível uma completa autojustificação do saber. Por isso Fichte, já desde seu primeiro escrito programático, assevera:

"Esse princípio - da doutrina-da-ciência e, por seu intermédio, de todas as ciências e de todo saber - não é, pois, suscetível de absolutamente nenhuma prova, isto é, não pode ser remetido a nenhuma proposição superior da qual, em sua relação com esse princípio, decorresse a sua certeza. Contudo, deve fornecer a fundação de toda certeza; deve, pois, apesar disso, ser certo, e alias ser certo em si mesmo, em função de si mesmo, $e$ por si mesmo." (GA I, 2, $120 \mathrm{BWL})^{12}$

18 Mas o que permite estabelecer uma tal autojustificação do saber? Como seria possível demonstrar a necessidade deste princípio último, "certo em si mesmo", se o mesmo não é "suscetível de absolutamente nenhuma prova"? Além disso, como podemos ter consciência dessa certeza que ultrapassa toda forma de demonstração ou prova a partir de proposições? A resposta de Fichte para esse problema, resposta que sem dúvida determina o desenvolvimento de todo seu projeto filosófico subseqüente, é a seguinte: "só na intuição repousa e consiste o saber." (GA II, 6, 138 WL 1801/02) ${ }^{13}$

"Fichte concebe a doutrina-da-ciência assim em um sentido forte como "scientia intuitiva". Além disso, ele relaciona a esse conceito uma identificação substancial entre a metodologia da doutrina-da-ciência e aquela da geometria: a doutrina-daciência não só parte de postulados, tal como a geometria; ela também pode, como essa última, se desenvolver completamente como teoria intuitiva construtiva - ela é uma "Mathesis do Espírito". ${ }^{14}$

19 A doutrina-da-ciência, enquanto teoria de todo o saber, deve estar fundamentada em uma pura intuição. Mais do que isso, na teoria de Fichte, esse saber do saber precisa estar fundamentado em uma forma de intuição que não seja receptiva, isto é, que não se encontre dependente de um objeto que causa sua afecção, portanto, que não seja uma intuição sensível. A certeza indubitável que fundamenta todo saber, e assim justifica o sistema da razão, só pode ser alcançada através de uma intuição intelectual. Mas o que exatamente significa 'intuição intelectual'? Eis como Fichte, já nas primeiras linhas da quinta seção de sua Segunda Introdução, define o conceito:

"Esse intuir de si próprio que se requer do filósofo, na realização do ato a partir do qual o Eu surge para ele, denomino intuição intelectual. Ela é a consciência imediata de que eu atuo, e do que eu faço: ela é aquilo a partir do qual eu sei algo, porque eu o faço. Que exista uma tal faculdade da intuição intelectual é algo que não se permite demonstrar por conceitos, nem se pode construir a partir de conceitos aquilo que ela é. Cada um deve encontrá-la de modo imediato em si mesmo, ou jamais a conhecerá. A exigência de que se deva demonstrá-la através de um 
raciocínio é algo ainda mais extraordinário do que o seria um cego de nascença exigir a alguém que lhe explicasse, sem que ele precisasse enxergar, o que as cores são." (GA I, 4, 216 s. EE) intuição intelectual, como se afirma na segunda parte do trecho citado, vejamos em detalhe quais elementos fazem parte da definição desse conceito. Fichte define primeiramente a intuição intelectual como um "intuir a si próprio", e essa intuição de si deve ser realizada pelo filósofo. Considerando-se apenas essa parte da definição, ainda não se tem clareza sobre o que exatamente constitui uma intuição de si. Certamente não se trata aqui de uma intuição dos estados internos do sujeito, pois uma tal intuição lida apenas com um múltiplo de fenômenos unificados no tempo.

21 Na seqüência da definição, Fichte complementa a primeira observação, mostrando que a realização dessa intuição de si é a realização do "ato a partir do qual o Eu surge" para o filósofo. Agora, a definição fichtiana esclarece que a idéia de um Eu só "surge" para o filósofo a partir desse ato de intuir a si mesmo. O conceito de Eu é produto de um ato, que por sua vez é sinônimo de uma intuição. Mas se o ato é realizado pelo próprio filósofo, então o agir do filósofo produz o conceito de $\mathrm{Eu}$. No entanto, essa complicada cadeia de implicações só existe aqui porque ainda não se considerou uma simples identidade, a saber, a identidade entre o Eu produzido e o Eu que atua (neste caso, o do filósofo). Por isso, se o eu do filósofo produz aquele eu, ele simplesmente está produzindo a si mesmo.

Como terceiro elemento dessa definição, Fichte acrescenta o seguinte: essa intuição intelectual, enquanto ato de construção do Eu, é uma "consciência imediata" tanto da ação como do produto dessa mesma ação. Aqui surge uma dificuldade com relação à expressão 'consciência imediata', pois não parece muito claro em que sentido podemos compreender uma consciência imediata de alguma coisa, na medida em que a preposição 'de' parece já sempre indicar uma relação intencional da consciência, uma referencia a algo outro que é visado por ela. A dificuldade se agrava na medida em que tal consciência é tomada como sinônimo da ação realizada pelo sujeito e, ao mesmo tempo, deve ser consciência "de que eu atuo". A única saída para esse problema seria mostrar que a consciência é, de fato, uma ação.

A meu ver, tanto no emprego do neologismo 'Tathandlung' da GWL, (cf. GA I, 2, 255) quanto na retomada do conceito de intuição intelectual a partir de 1797, o intuito principal de Fichte consiste justamente em esclarecer essa identidade entre ação e consciência. Se for acrescentada ainda a tese de que a consciência, por si só, pode ser compreendida como uma forma de conhecimento, isto é, como uma capacidade cognitiva, é possível então determinar tal identidade também como identidade entre o agir e o saber. Mais ainda, essa identidade fundamental será demonstrada por Fichte como aquilo que constitui o eu enquanto eu, ou seja, a identidade entre agir e saber deverá se revelar condição de possibilidade do próprio eu autoconsciente. Zöller confirma essa hipótese interpretativa:

"De acordo com Kant, um ser que possui intuição intelectual é um ser no qual conhecer e fazer coincidem. A descrição de Fichte do Eu em termos de uma 'intuição intelectual' pode ser vista como uma adaptação da noção kantiana de uma mente na qual agir e conhecer estão originariamente unidas. Segundo a concepção de Fichte, o eu da intuição intelectual é um fazer que também é um saber, e vice versa." 15

A partir dessa complexa relação entre os conceitos de sujeito, ação, conhecimento e consciência, talvez seja possível compreender um pouco melhor em que sentido a idéia de intuição intelectual pode ser fundamento de toda certeza, isto é, de que modo essa 
intuição pode justificar de forma apodíctica o próprio sistema da razão. Afinal, a afirmação de Fichte não deixa dúvidas sobre esse ponto: "esta intuição intelectual é o única ponto de vista (Standpunkt) firme para toda filosofia. A partir dela se pode esclarecer tudo aquilo que aparece na consciência; mas também somente a partir dela." (GA I, 4, $466 \mathrm{ZE}$ )

Retomando ainda a definição do conceito de intuição intelectual analisada mais acima, encontra-se ali uma indicação direta daquela relação complexa mencionada, quando Fichte afirma que a intuição intelectual "é a consciência imediata de que eu atuo, e do que eu faço". Ter uma consciência imediata de que eu atuo é o mesmo que me conhecer como um agente, ou melhor, como agindo. Além disso, uma ação é sempre uma ação determinada, de modo que só posso conhecer a mim próprio enquanto agente a partir dessa ação determinada (e, por conseguinte, conheço também tal determinação). Assim, podemos compreender por que Fichte postula uma ligação necessária entre a intuição intelectual e a intuição sensível, mostrando inclusive - o que pode sem dúvida acarretar sérios problemas para sua teoria - que cada qual jamais pode constituir isoladamente um estado determinado de consciência. Eis a passagem em questão:

"Essa intuição, no entanto, jamais aparece isolada, como um ato completo da consciência; assim como também a intuição sensível jamais aparece isolada, nem completa à consciência, mas ambas devem ser conceituadas. Não apenas isso, mas a intuição intelectual está também sempre vinculada a uma intuição sensível. Não posso me encontrar como agindo, sem encontrar um objeto sobre o qual eu ajo, em uma intuição sensível que será concebida; sem projetar uma imagem daquilo que pretendo produzir, a qual igualmente será concebida." (GA I, 4; $217 \mathrm{ZE})$

Fica claro a partir da observação de Fichte que a determinação do agir exige um objeto sobre o qual se age, e tal objeto é por sua vez determinado através da interação entre intuição sensível e conceito. Claro também está o fato de que minha ação exige para sua determinação uma finalidade, como expressa o conceito de 'imagem' (Bild) utilizado por Fichte. No entanto, permanece não esclarecido por que a própria intuição intelectual, enquanto fundamento de toda e qualquer consciência, não é capaz por si só de delimitar um estado completo de consciência.

Não se entende também em que sentido Fichte pode afirmar que a intuição intelectual, para delimitar um estado de consciência, deve ser "conceituada". Afinal, não há distinção mais radical presente na obra de Fichte do que justamente a contraposição entre intuição intelectual e conceito (ou conceituar). Tal contraposição desempenha papel crucial, por exemplo, no contexto teórico da WL 1804.

Uma interpretação plausível dessa relação ou vínculo necessário entre a intuição intelectual e intuição sensível é proposta por F. Neuhouser. De acordo com o autor, o vínculo necessário entre as duas formas de intuição representa o estado originário da consciência comum, a qual, em comparação com a compreensão filosófica da consciência, "não está ela própria ciente dessa estrutura dúplice." ${ }^{16}$ Neuhouser utiliza o seguinte trecho do texto de Fichte para fundamentar essa sugestão:

"Assim o filósofo encontra essa intuição intelectual como fato da consciência (para ele isso é um fato; para o eu originário, um estado-de-ação [Tathandlung] ${ }^{17}$ ), não de modo imediato, como fato isolado de sua consciência, mas na medida em que ele distingue aquilo que aparece unificado na consciência comum, e decompõe o todo em seus elementos." (GA I, 4, $218 \mathrm{~s}$. ZE)

$\mathrm{O}$ aspecto mais relevante da proposta de Neuhouser consiste em indicar o modo como a intuição intelectual acompanha cada intuição sensível de um determinado objeto. 
Seguindo sua interpretação, a consciência representada pela expressão 'intuição intelectual' deve ser compreendida, à la Sartre, como uma consciência “não-tética", isto é, como uma espécie de consciência subliminar, potencial, presente apenas de modo implícito simultaneamente em todos os atos da "autoconsciência reflexiva". ${ }^{18}$ Nesse sentido, uma diferença importante entre esses dois modos de consciência, seguindo a interpretação de Neuhouser, residiria no seguinte: se a consciência reflexiva envolve sempre uma indicação explícita de seus objetos e pode ser compreendida como um direcionamento intencional ao objeto investigado (mesmo que esse objeto seja a própria consciência), a consciência pré-reflexiva ou não-intencional, por outro lado, é um elemento presente de forma constante em todos processos conscientes, mas que só vem a tona a partir de sua tematização pela consciência reflexiva. Por isso, o conceito de intuição intelectual é muitas vezes compreendido apenas como uma condição de possibilidade da consciência, uma mera possibilidade que só se torna efetiva a partir do pensamento conceitual sobre o eu. Essa interpretação é inclusive corroborada em parte por algumas passagens do próprio texto de Fichte.

No entanto, se o objetivo principal da teoria fichtiana da intuição intelectual é fundamentar todo conhecimento de maneira apodíctica, como foi sugerido anteriormente, e, além disso, se para realizar tal fundamentação de modo autônomo, isto é, enquanto autofundamentação do próprio conhecimento, essa intuição intelectual precisa constituir uma espécie de atividade cognitiva originária, essa interpretação branda para o sentido da expressão 'intuição intelectual' - que equipara a mesma ao 'eu penso' kantiano - se mostra de todo insuficiente. O próprio Neuhouser estava ciente desse problema central:

"Fichte parece afirmar que, mesmo que o eu só se constitua plenamente como objeto na consciência reflexiva, ele não surge primeiro ali. Ao invés disso, já na intuição intelectual o eu se encontra presente a si mesmo de alguma forma - sem dúvida não enquanto um eu particular, individual, mas simplesmente 'como um sujeito', como 'alguma coisa consciente' [das Bewußtseiende]." 19

31 Ainda que a expressão "alguma coisa consciente" ${ }^{20}$ não se mostre propriamente adequada para traduzir o termo fichtiano 'das Bewußtseiende', a observação de Neuhouser retoma o cerne da questão: a intuição intelectual precisa consistir em uma atividade consciente do sujeito. ${ }^{21}$ Mais do que isso, essa fusão entre ação, consciência e subjetividade deve gerar um conhecimento, e um conhecimento absolutamente certo. Como mais de uma vez afirma Fichte, o princípio da autoconsciência, i.e. a intuição intelectual, deve fundamentar toda outra forma de consciência:

"De acordo com a doutrina-da-ciência, toda consciência é determinada pela autoconsciência, i.e., tudo que aparece na consciência está fundamentado, dado, produzido pelas condições da autoconsciência; e um fundamento para o mesmo fora da autoconsciência simplesmente não existe.” (GA I, 4229 ZE)

III

Como então é possível determinar essa autofundamentação apodíctica do saber a partir da intuição intelectual? Para tentar resolver esse problema, será preciso voltar à definição fichtiana dessa expressão. Pode-se dizer que o elemento mais fundamental dessa definição se encontra na afirmação da identidade entre agir e saber. Como diz Fichte já na primeira definição supracitada do conceito, a intuição intelectual "é aquilo a partir do qual eu sei algo, porque eu o faço." (GA I, 4217 ZE) 

procedimentos realizados pelo eu ou pela consciência, mas essa identidade permite por sua vez ao autor identificar ambos processos como sendo o próprio "objeto" dessa consciência. Aqui deve-se ter muita cautela no uso dos termos, pois ao se considerar o agir e o saber como 'objetos' da consciência corre-se o risco de indevidamente transformar a "relação" imediata entre a consciência e sua performance originária autoreferente em uma relação reflexiva ou intencional entre consciência e objeto.

Mas o que significa postular uma identidade entre agir e saber? Além disso, o que pode significar a idéia aparentemente circular de que temos consciência da própria ação da consciência? Que espécie de ação é essa? Evidentemente, Fichte não está se referindo aqui a uma ação concreta que exercemos no mundo, e sim à ação ideal constitutiva da consciência enquanto tal. Pode-se dizer sem mais que essa ação é equivalente à nossa atividade de pensamento? Acredito que parte dos problemas aventados pelos críticos da doutrina-da-ciência de Fichte, no tocante à inconsistência interna desse sistema teórico, provém da resposta afirmativa para tal questão.

Pelo contrário, a teoria de Fichte parece designar dois níveis de ação da consciência, um correspondente ao modo de ação originário da mesma, um puro agir que retorna a si mesmo (e que ainda precisa ser esclarecido), outro que corresponde aos modos de ação da consciência determinada, cujas determinações se dão através do próprio pensamento (atividade ideal) ${ }^{22}$. Eis como Fichte expressa essa distinção:

"[o filósofo] tem um conceito do agir em geral e enquanto tal, em oposição ao também já conhecido ser; e um conceito desse agir específico, que em parte é um agir da inteligência como tal, atividade puramente ideal, de modo algum uma atuação real através da faculdade prática em sentido estrito, em parte é, dentre as possíveis ações dessa inteligência, um agir que é apenas um retornar a si mesmo, e não um dirigir-se para fora a um objeto." (GA I, 4, $245 \mathrm{ZE}$ )

Na verdade, mesmo essa passagem citada pode induzir ao erro de interpretação aludido logo acima. Se esse simples "retornar a si mesmo" efetuado pela consciência é, como afirma Fichte, uma "dentre as possíveis ações da inteligência", o autor parece indicar aqui apenas uma atividade reflexiva do pensamento, e portanto uma forma intencional de consciência, mesmo que sua intencionalidade esteja direcionada para a própria consciência. Como reforço a essa forma de interpretar a estrutura fundamental da consciência se apresenta o fato de que o próprio Fichte oscila em sua posição. Ao mesmo tempo em que a intuição intelectual deve ser uma forma de consciência atual, imediatamente presente ao sujeito, ela parece sempre estar inacessível em sua forma pura ou isolada. ${ }^{23}$

De acordo com a ambigüidade exposta acima, torna-se necessário esclarecer de que modo Fichte pretende garantir o caráter apodíctico da intuição intelectual. Como se torna possível evitar a objeção hegeliana de que a intuição intelectual, tal como proposta pela teoria de Fichte, é, em última instância, completamente arbitrária? Mais do que isso: em que medida a teoria da intuição intelectual é realmente adequada para fundamentar de modo último a própria estrutura cognitiva racional humana? Como se dá tal fundamentação?

38 A tentativa de compreender aquilo que constitui originariamente o próprio Eu, isto é, explicitar a autorelação constitutiva dessa pura atividade que, enquanto intuição intelectual, é ao mesmo tempo consciência e saber, pode talvez trazer alguma luz sobre as difíceis questões levantadas. Ainda que sob forma de esboço, tamanha a complexidade do

Revista de Estud(i)os sobre Fichte, 1 | 2010 
problema, gostaria de sugerir, de acordo com o exemplo de construção geométrica utilizado por Fichte no início de sua Exposição da Doutrina-da-Ciência de 1801/2, um caminho possível de leitura para a definição de intuição intelectual aqui investigada.

Ao requerer a descrição de um triângulo qualquer, Fichte pretende incitar no seu interlocutor a observação do próprio ato de construção dessa forma geométrica. A partir da performance dessa construção, e da observação simultânea dessa performance, é possível ao interlocutor captar intuitivamente, de maneira imediata, a validade universal de sua construção. 0 exemplo traçado pela imaginação do interlocutor revela um sentido geral àquela construção que ultrapassa o conjunto específico de suas linhas e dimensões. Em outras palavras, o experimento proposto por Fichte pretende indicar, mesmo que através de uma simples imagem, como a idéia de certeza está intimamente vinculada à idéia de construção de um determinado conceito, ou ainda, de um saber determinado. (cf. GA II, 6, 135-138 WL 1801/02)

Além disso, o método dessa construção será compreendido por Fichte como uma passagem daquilo podemos realizar diretamente a partir de uma intuição simples, como o traçar de um linha, em direção à unificação desses elementos no conceito. A certeza sobre a universalidade da construção do triângulo, portanto, não surge a partir de uma definição nominal do que seja um triângulo, mas sim da possibilidade de repetir o experimento na própria intuição.

41 Da mesma forma, a compreensão de um conceito, em certo sentido, sempre já antecede o próprio conceito. Damos nomes àquilo que podemos construir ou já construímos através de nosso sistema simbólico. Mas o próprio sistema simbólico, se assim pudéssemos denominar o conjunto de representações que constitui nosso campo semântico, ou nossa linguagem, não pode surgir a partir de si mesmo. Como bem observa I. Thomas-Fogiel, "a intuição intelectual é conhecida pelo ato contido em toda proposição. Isso que é universal, não é tal ou qual proposição, mas o ato de enunciar." ${ }^{24}$

Assim como o traçar da linha ${ }^{25}$ precede o triângulo, assim também "a intuição é e permanece aquilo que subjaz ao conceito e o que nele é compreendido [das in ihm Begriffene]. Não podemos inventar [sich erdenken] ou criar absolutamente nada pelo pensamento; podemos pensar apenas o que é intuído imediatamente". (GA I, 4, $245 \mathrm{ZE}$ ) Caso contrário, não houvesse um tal vínculo profundo entre a capacidade de representação, ou mesmo do pensamento abstrato, e um modo de agir correspondente da consciência, isto é, uma intuição, "a possibilidade de todo pensamento estaria condicionada por um outro pensamento, e pelo pensamento desse pensamento"; e, por conta disso, o perplexo filósofo exclama: "e gostaria de saber como deveríamos chegar então a um único pensamento.” (GA I, 4, $228 \mathrm{ZE}$ )

43 A doutrina-da-ciência pretende mostrar que justamente essa atividade pura de construção é o que constitui aquela instância que, depois da primeira Crítica kantiana, aparece como condição última de possibilidade e unidade de todo e qualquer juízo ou representação, a saber, a unidade da apercepção transcendental, denominada por Fichte simplesmente pelo coloquial 'Eu'. Em outras palavras, o fundamento último de todo conhecimento, o Eu, ou autoconsciência, não é propriamente um ser, mas uma pura atividade $^{26}$; uma atividade de construção do saber e, portanto, inevitável construção de si enquanto saber.

44 Assim, a certeza apodíctica de todo conhecimento se encontra, tal como em Descartes, fundamentada na certeza de si mesmo do Eu. Mas o que fundamenta a certeza de si do 
próprio Eu? Como se funda, para perguntar com Fichte, a certeza do princípio de toda certeza? A resposta adequada para esse problema só pode ser uma mera indicação, uma idéia ou proposição que representa figurativamente a ação a ser executada pela consciência de quem pergunta. Essa idéia já se encontra no escrito Sobre o Conceito da Doutrina-da-Ciência, publicação de 1794 pouco anterior à GWL, onde Fichte esclarece:

"Aquilo que a doutrina-da-ciência estabelece é uma proposição pensada e posta em palavras; aquilo que, no espírito humano, corresponde a essa proposição é uma ação qualquer dele, que em si não teria necessariamente de ser pensada. Para esta ação não se pode pressupor nada a não ser aquilo sem o qual ela seria impossível como ação; e isto não é pressuposto tacitamente, mas é ocupação da doutrina-da-ciência estabelecê-lo clara e determinadamente, e como aquilo sem o qual a ação seria impossível." (GA I, 2, 148 BWL) ${ }^{27}$

Por isso não há meios de encontrar uma definição conceitual denotativa para o saber de si do eu ou da consciência, caso seja ele verdadeiramente um saber de si, e não somente um pensar sobre si. Por isso também Fichte insiste no fato de que a intuição intelectual é uma compreensão do puro agir da consciência, mas sobretudo uma compreensão desse agir através do próprio agir. Nesse sentido, a única forma de realizar essa compreensão in actu, como sugere o autor, é através da própria intuição. Intuição tem, pois, o sentido de um conhecimento processual, ou melhor, indica a realização de um procedimento e a consciência que temos ao longo dessa realização. Isso não exclui a determinação de objetos da representação fixados pelas regras do entendimento. Pelo contrário, a consciência do filósofo analisa justamente a constituição dessas representações fácticas determinadas na consciência comum. A descoberta do puro agir originário sempre parte de um agir determinado. Assim, o sentido do conceito de ação pura da consciência se define apenas de modo negativo, através de sua oposição ao conceito de ser (conceito cuja definição, na teoria de Fichte, significa toda e qualquer determinação objetiva, mesmo quando interna à própria consciência) ${ }^{28}$.

"O que seja o agir, isso só pode ser intuído, não pode ser desenvolvido a partir de conceitos e se comunicar através de conceitos; mas aquilo que reside nessa intuição é compreendido através da contraposição ao mero ser. Agir não é o ser, e o ser não é um agir; uma outra determinação a partir de seu puro conceito não é possível; para [conhecer] sua verdadeira essência, devemos nos dirigir à intuição." (GA I, 4, $215 \mathrm{ZE}$ )

A certeza apodíctica da intuição intelectual, enquanto fundamento de toda certeza apodíctica, em última instância se mostra como simplesmente indemonstrável. "Que exista uma tal faculdade da intuição intelectual", como assevera Fichte, "é algo que não se permite demonstrar por conceitos, nem se pode construir a partir de conceitos aquilo que ela é. Cada um deve encontrá-la de modo imediato em si mesmo, ou jamais a conhecerá." (GA I, 4, $217 \mathrm{ZE}$ )

\section{NOTAS}

1. O Ensaio inclui a Primeira Introdução à Doutrina-da-Ciência (EE), a Segunda Introdução à Doutrinada-Ciência (ZE) e o Primeiro Capítulo (VND). As traduções de modo geral são minhas, exceto para 
alguns textos de Fichte, quando será indicada página da tradução (Fichte. ${ }^{\text {Trad. de Torres Filho, } 2^{a} \text { ed. são }}$ Paulo 1984.

2. Além do fato de que um conhecimento a priori é aquele por completo independente da experiência, Kant define essa propriedade, de um modo um tanto circular, a partir dos critérios de absoluta necessidade e universalidade. (Cf. KrV B 3-4) Sem dúvida a pergunta central da primeira Crítica, como são possíveis os juízos sintéticos a priori, esse "mistério" (KrV A 10) a ser desvelado, representa ao menos o plano de investigar a raiz dessa apodicticidade. Contudo, Fichte considerou a resposta kantiana insatisfatória. (cf. GA IV, 3, 325 WLnm)

3. Assim podemos compreender o tom irônico com que Fichte indiretamente critica Schelling, quando o acusa de ter construído um sistema metafísico dogmático fundamentado no ser, adicionando em seguida "a palavrinha Eu". (GA II, 8, 16 WL 1804²)

4. Cf. G.W.F. HEGEL, Differenz des Fichte'schen und Schelling'schen Systems der Philosophie. Em: Werke in 20 Bänden. Frankfurt a. M. 1970. T. 2: 9-139, em especial 50-52.

5. Por isso, ao comentar sobre o projeto hegeliano, E. Luft observa: “todo o seu esforço direcionase para a construção de um novo método capaz de sintetizar em um mesmo procedimento a criticidade da Filosofia da Reflexão e a sistematicidade do espinosismo de Schelling." (E. LUFT, As Sementes da Dúvida. Investigação Critica dos Fundamentos da Filosofia Hegeliana. São Paulo 2001: 114). De fato, dita tensão é um dos temas centrais discutidos nessa obra de E. Luft.

6. Em nota de rodapé, Fichte esclarece: "evitei até agora essa expressão para não conduzir à representação do Eu como uma coisa em si." (GA I, 4, $190 \mathrm{EE})$

7. Cf. além disso GA I, 4, 192, 196 EE; GA I, 4, 260 s. ZE; e GA IV 2, 20 ss. WLnm.

8. Nesse contexto surge a célebre sentença do filósofo: "a filosofia que se escolhe depende, portanto, do homem que se é; pois um sistema filosófico não é um utensílio morto, que se pode deixar de lado ou apanhar a seu bel-prazer, mas é animado pela alma do homem que o tem." (GA I, 4, $195 \mathrm{EE}$; trad. 67)

9. Fichte deveria ter acrescentado: com duas linhas finitas.

10. Trad. 255.

11. Trad. ibid.

12. Trad. 48 (grifo meu).

13. Trad. 257.

14. Н.-С. кLOTZ Selbstbewusstsein und Praktische Identität: Eine Untersuchung über Fichtes Wissenschaftslehre nova Methodo. Frankfurt a. M. 2002: 46-7. Como indica H.-C. Klotz, a expressão ‘ Mathesis do Espírito' é do próprio Fichte: cf. GA II 5, 334 Neue Bearbeitung der WL, 1800.

15. G. zöLLER “An eye for the I. Fichte's transcendental experiment”, em: D. E. Klemm e G. Zöller (eds.) Figuring the Self: Subject, Absolute, and Others in Classical German Philosophy. Albany 1996: 82.

16. F. NEUHOUSER, Fichte's Theory of Subjectivity. Cambridge 1990: 80.

17. P. Rohs equipara a atividade da intuição intelectual à tese fichtiana do pôr a si mesmo do Eu ( sich setzen), ou estado-de-ação (Tathandlung), tal como fomulado na primeira versão da doutrinada-ciência. Isso é de fato confirmado pelo próprio Fichte: "aquela pressuposição [de que a autoconsciência é o fundamento de toda consciência] e o pensamento do Eu como posto originariamente por si mesmo sejam completamente idênticos". (GA I, 4, 216 ZE) Rohs observa, no entanto, que não é possível uma definição positiva sobre o que exatamente constitui essa atividade de pôr a si mesmo. Por isso, como observa o autor, Fichte sempre acaba justificando essa teoria do estado-de-ação a partir da consciência da liberdade. (cf. P. ROHS Johann Gottlieb Fichte. München 1991: 42)

18. Utilizando ao invés dos termos 'autoconsciência reflexiva' e 'autoconsciência implícita ou não-tética' a caracterização de cunho husserliano 'consciência intencional e não-intencional', H.C. Klotz apresenta uma explicação similar: “Toda consciência intencional contém assim uma consciência imediata do pensamento, que não funciona como intuição do objeto intencional, e que por conseguinte pode ser caracterizada como 'o subjetivo' nessa consciência. Essa função 
essencial da consciência distingue a 'intuição' do próprio pensamento daquela intuição sensível contida na consciência intencional." (op. cit. 64)

19. F. NEUHOUSER , op. cit. 85.

20. No original: conscious something. Outra tradução possível: 'um algo consciente'. Para expressar melhor a idéia de Fichte, talvez seja necessário algo como 'o consciente' ou 'aquele que é consciente'. Até mesmo a expressão 'aquele que tem consciência' provoca confusão, como indica explicitamente Fichte na seguinte passagem da WLnm: “Alguém diz, 'eu tenho consciência' como se a consciência fosse uma propriedade acidental do eu. Esta distinção entre a consciência e o eu é introduzida posteriormente, e a filosofia precisa explicar o motivo para se fazer tal distinção. É verdade que devo atribuir a mim mesmo outras determinações ou predicados além da consciência, mas ainda assim, todas as ações devem passar pela representação. Portanto, tudo que deve existir para nós, é apenas uma consciência. Não é correto pensar que o eu se torna consciente através de algo outro. O eu nada mais é do que sua própria atividade." (GA IV, 2, 24 WLnm) Esse aspecto se revela na verdade como ponto central da própria teoria de Fichte. (cf. GA II, 6, 141 s. WL 1801/2)

21. Por isso Neuhouser, com razão, sugere que a idéia de um pensamento sem consciência de um $\mathrm{Eu}$, dentro do contexto teórico de Fichte, é equivocada. (cf. op. cit. 84)

22. F. Neuhouser indica que a distinção feita por Kant (em KrV B 132) entre a pura apercepção e a consciência do "eu penso", na medida em que essa última seria gerada ou produzida pela primeira, pode ter levado Fichte a estabelecer essa diferença. (cf. op. cit. 96, nota 49)

23. De fato, o autor parece assumir que só temos conhecimento da intuição intelectual a partir de uma inferência analítico-regressiva desde fatos da consciência comum: "Contudo, se devemos aceitar que não é possível uma consciência imediata e isolada da intuição intelectual, como então o filósofo chega ao conhecimento e à representação isolada da mesma? Respondo: sem dúvida, da mesma forma como ele chega ao conhecimento e à representação isolada da intuição sensível, através de uma inferência [Schluß] a partir dos fatos da consciência evidentes." (GA I, 4, 218 ZE)

24. I. THOMAS-FOGIEL, Critique de la Représentation: Étude sur Fichte. Paris 2000: 61.

25. E não a linha traçada. Cf. GA I, 7, 160 [Ankündigung] Seit sechs Jahren. 1801

26. "[...] a essência do idealismo transcendental em geral, e de sua apresentação na doutrina-daciência em particular, consiste em que o conceito de ser não é considerado como conceito primário e originário, mas apenas como deduzido, e de fato deduzido de sua contraposição à atividade, portanto considerado apenas como um conceito negativo. $O$ único positivo para o idealista é a liberdade; ser é a mera negação dessa liberdade. Apenas sob essa condição o idealismo encontra um fundamento firme e permanece em acordo consigo mesmo". (GA I, 4, 251 s. ZE)

27. Trad. 32 .

28. Eis outro modo como Fichte descreve essa relação: “o conceito, onde quer que apareça, nada mais é do que a atividade do próprio intuir, não captada como agilidade [Agilität], mas como repouso [Ruhe] e determinidade [Bestimmtheit]". (GA I, 4, 280 VND) Trad. 185.

\section{RESUMOS}

This paper analyses Fichte's concept of intellectual intuition paying special attention to Fichte's proposal of transforming the point of view in constructing knowledge. Therefore the focus will 
be not directed, as in traditional interpretations, to the the problem of the structure of subjectivity as objective foundation of reality, but to the process of construction of consciousness. I will argue that this idea of genesis of (self)consciousness represents the originality of Fichte's philosophy.

ÍNDICE

Keywords: (intellectual) intuition, Hegel, (epistemological) constructivism

\section{AUTOR}

THIAGO S. SANTORO

Goiânia, Brasil 